\title{
An Experimental Study of Diesel Spray Impingement on a Flat Plate: Effects of Injection Conditions
}

\author{
Xiucheng Zhu, Le Zhao, Zhihao Zhao, Nitisha Ahuja, \\ Jeffrey Naber, Seong-Young Lee* \\ Michigan Technological University, Houghton, MI, USA \\ *Corresponding author: sylee@mtu.edu
}

\begin{abstract}
Advanced injection strategies for internal combustion engines have been extensively studied although there still exists a significant fundamental knowledge gap on the mechanism for high-pressure spray interaction with the piston surface and chamber wall in the internal combustion engine. The current study focuses on providing qualitative and quantitative information on spray-wall impingement and its characteristics by expanding the range of operating parameters under engine-like conditions. Parameters considered in the experiment are ambient gas and fuel injection conditions. The test included the non-vaporizing spray at the different ambient density $(14.8,22.8$ and $30 \mathrm{~kg} / \mathrm{m}^{3}$ ) and injection pressure (1200, 1500 and $1800 \mathrm{bar}$ ) with the isothermal condition (ambient, and plate temperatures of $423 \mathrm{~K}$ ). The test was conducted in the constant-volume vessel with the 60 -degree impinging spray angle relative to the plate. The free spray and impinged spray properties were qualitatively analysed based on Mie and schlieren images. The results showed that the lower ambient density and higher injection pressure tended to result in relatively higher impinged spray height. The expanding shape of the impinged spray on the wall showed the oval shape.
\end{abstract}

\section{Keywords}

free spray; impinged spray; wall-impinged expanding spray; flat plate

\section{Introduction}

Internal combustion engines (ICEs) have been the dominant power supply for automobiles since the $20^{\text {th }}$ century and will keep playing an important role in transportation sectors in the coming decades. Increasingly stringent fuel consumption and emission standards are driving automotive research. Advanced injection strategies such as increasing injection pressure, multiple injections, injection timing control, and many others can enhance fuel efficiency in the application of direct injection spark ignition (DISI) engines and direct injection (DI) diesel engines. The DISI and DI diesel engines are able to achieve such higher efficiencies by means of better spray atomization and air-fuel mixing. Besides injection parameters mentioned above, the spray-wall interaction plays a critical role in fuel spray dispersion and subsequent combustion event [1-3]. The fuels used in ICEs undergo the vaporization process and mix with air before combustion. However, the fuel spray may impinge on the engine surfaces before it is fully vaporized [4]. The non-vaporizing spray possibly impinges on the cylinder head or liner in DI engines and even on the inlet valves in port fuel injected (PFI) engines. The spray-wall impingement usually forms a liquid film on the wall, which is referred to wall-wetting phenomenon [5]. The fuel deposition on the wall may survive during the combustion phase, resulting in producing unburned hydrocarbon $(\mathrm{HC})$ and particulate matter (PM) emissions [6-8]. Especially in cold operation (such as cold start and warm-up), the wall wetting in PFI engines becomes dominant mechanism for engine-out HC emissions [9-13]. When the spray droplets hit the wall, they may undergo the following scenarios: stick, rebound, and splash, depending on the Weber number and droplet impact dynamics [14]. It was also reported that the impinging process could enhance the air-fuel mixing [15]. In addition, a heated plate may also lead to the heating or secondary evaporation of the impinged droplets.

Early work in an optically accessible engine has characterized the spray-wall interaction phenomena and measured the after-collision spray properties such as droplet sizes and film thickness on wall. Siewert et al. [16] performed experiments in a 103-mm bore DI single cylinder diesel engine (reentrant-shaped piston bowl) to explore the effect of the calculated amount of liquid spray that misses the piston bowl. By changing spray impacting angle and injection timing, a different amount of liquid spray that misses the piston bowl was acquired in their study, which was highly linked to the $\mathrm{HC}, \mathrm{CO}$, and smoke formation. Stanglmaier et al. [5] experimentally investigated the effect of wallwetting on the $\mathrm{HC}$ emissions in an optical gasoline-fuelled SI engines. A spark-plug mounted directional injection probe was used to study the impingement effects on $\mathrm{HC}$ emissions independent from all other $\mathrm{HC}$ sources, by operating engine on pre-mixed liquefied petroleum gas (LPG). Their results argued the importance of the impingement location, which significantly influenced the $\mathrm{HC}$ emission generation regardless of the injection timing and coolant temperature.

Besides engine spray-wetting test, well-controlled constant volume chambers have been utilized to acquire a higher level of visualization access and identify precise boundary conditions near the wall surface such as film thickness 
and heat flux. Akop et al. [17] captured the entire injection event using high-speed shadowgraph and weighted the film mass on the wall to explore the adhesion characteristics of the diesel impinging spray. They found that the adhered mass kept constant by changing disk diameter from $25 \mathrm{~mm}$ to $50 \mathrm{~mm}$, and the thickness of the adhesion liquid became lower with increasing injection pressure. Furthermore, the ratio of adhered fuel mass to total injected mass tends to decrease with an increase of the disk inclination. Lindgren et al. [18] studied the spray-wall interactions in a spray chamber with simulated engine conditions using an AVL VisiScope. The images indicated that most of the reflected drops were carried away from the impinging point by means of a wall jet and very few drops were bounced away with a large reflection angle. Meanwhile, Phase Doppler Anemometry (PDA) was also employed to measure the size and velocity of droplets reflected from a wall. They observed a secondary break-up at the wall, resulting in smaller drops. A PDA and high-speed imaging methods were used by Montorsi et al. [19] in a high pressure and temperature spray rig to measure the surface temperature with three coaxial thermocouples. The measured temperatures were used to calculate heat fluxes using a one-dimensional transient heat conduction model. Four different breakup models (i.e. Reitz-Diwakar, Hsiang-Faeth, Pilch-Erdman, and Kelvin-Helmholtz (KH)Rayleigh-Taylor (RT), see Table 3 in Ref. [19]) were compared with their test results and showed sufficient agreement with experimental results except for the overestimation in liquid penetration.

Film formation is one of the important properties as a result of spray-wall impingement. Senda et al. [20] applied laser-induced fluorescence (LIF) to quantitatively measure the adhered fuel film on a flat glass under atmospheric pressure and room temperature. The adhered fuel measured by LIF showed almost $40 \%$ of the total injection quantity at $10 \mathrm{~ms}$ after the end of injection while the adhered fuel is relatively insensitive to injection duration. They also classified the radial spreading velocity into three stages: early constant velocity stage, gradually decreasing stage, and fully stop stage. Another optical method of measuring the spatial and temporal thickness of the wall liquid film is the Refractive Index Matching (RIM) technique. RIM utilizes the similar refractive indexes between glass/quartz and fuel to characterize the impingement deposition on the wall. The thickness of the wetted area on a roughed glass surface has a relationship with the scattering light intensity. Drake et al [6]. have used this method to measure the film thickness of the impinged spray and the total mass injected on a piston top in an optical engine to successfully establish a correlation between $\mathrm{HC}$ emissions/PM and the film thickness variation.

Montanaro et al. [21] studied the effects of the injection pressure and wall temperature on the atomization and vaporization processes in their constant volume chamber. High-speed Mie-scattering and schlieren diagnostics were used to capture the impinged liquid and vapor widths (maximum radial penetration) and maximum heights. They found that the impinged spray widths showed a proportional increase with wall temperature, and the heights for both impinged liquid and vapor were proportional to the injection pressure.

The objective of the current study is to experimentally explore the effects of the injection pressures and ambient densities on the spray-wall impingement characteristics including free spray penetration, spray angle, impinged spray height, impinged spray radius, and expansion rate. The spray-wall test in the current work was carried out in a high pressure-temperature constant volume vessel with a wide range of diesel engine conditions. High-speed visualization diagnostics including Mie-scattering and schlieren techniques were used to characterize the rebound/impinged spray formation and spray wall interactions under different injection pressures and ambient conditions. Injection pressures were varied from 1200 bar to 1800 bar and ambient densities changed from 14.8 $\mathrm{kg} / \mathrm{m}^{3}$ to $30 \mathrm{~kg} / \mathrm{m}^{3}$. The detailed experimental results obtained in the study will support the validation of the existing spray-combustion CFD codes in future.

\section{Experimental setup}

This spray-wall impingement experiment was carried out in a high-pressure, high-temperature constant volume vessel (CV) as shown in Figure 1. The CV is $1.1 \mathrm{~L}$ cubic chamber with a good optical access. Three types of port windows were installed on all the six surfaces of the cube: $101 \mathrm{~mm}$ diameter transparent window (sapphire), blank metal window, and injector window. The unobstructed orthogonal optical access is coupled with high-speed imaging techniques to study spray development. The impinging plate was mounted on the bottom window, and the injector was installed on one of the side windows. Three ports on the eight vertices of the chamber are used for the intake/ exhaust of chamber ambient gas, and a mounted dynamic pressure transducer. A Kistler 6001 piezo-electric dynamic pressure transducer coupled with a Kistler 5044a charge amplifier was used to measure the CV pressure and detailed vessel information is available in Ref. [14].

A single-hole diesel injector (off-axis injector nozzle) was mounted in the middle of the injector window, which resulted in the vertical distance $(40 \mathrm{~mm}$ for metal window and $52 \mathrm{~mm}$ for transparent window) between the injector tip and impinging window surface. For both the front view and side view spray measurement (see the left-top corner in Figure 1), the optical arrangement of simultaneous Mie scattering for the front view and schlieren for the side view is shown in Figure 1. A high-intensity pulsed LED1 with a pin-hole aperture is the light source for schlieren while additional LED2 and LED3 for the volumetric Mie scattering imaging are placed in front of the optical access 
of the chamber. For the bottom view and front view measurement, camera 1 is placed below the vessel with a 45 degree reflector. The test conditions and fuel properties are listed in Table 1.

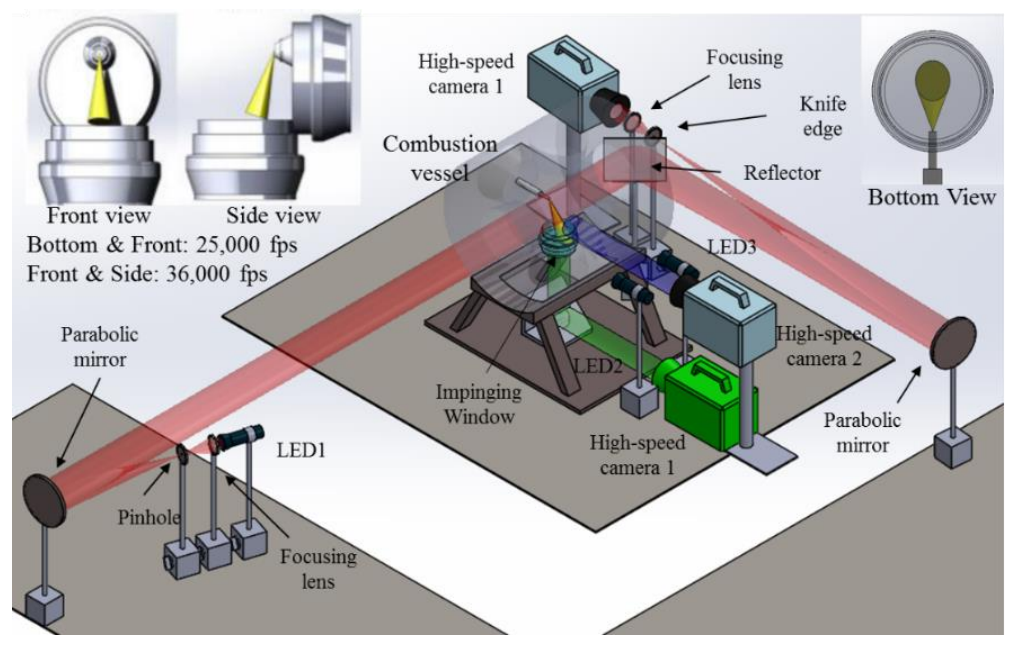

Figure 1. Optical setup for Mie and schlieren diagnostics with front/side/bottom view.

Table 1. Test conditions and fuel properties

\begin{tabular}{|c|c|c|c|}
\hline \multicolumn{2}{|c|}{ Injector conditions } & \multicolumn{2}{c|}{ Ambient and boundary conditions } \\
\hline Nozzle outlet diameter & $200 \mu \mathrm{m}$ & Ambient gas temperature & $423 \mathrm{~K}$ \\
\hline Nozzle number & single-hole & Ambient gas density & $14.8-30 \mathrm{~kg} / \mathrm{m}^{3}$ \\
\hline Nozzle K factor & 0 & Ambient gas & $\mathrm{N}_{2}$ \\
\hline $\begin{array}{c}\text { Orifice orientation } \\
\text { relative to injector axis }\end{array}$ & $\begin{array}{c}\alpha=60 \text {-degree (inclined } \\
\text { angle: } 120 \text {-degree) }\end{array}$ & $\begin{array}{c}\text { Distance from injector tip } \\
\text { to plate }\end{array}$ & $\begin{array}{c}\text { Metal: } 40 \mathrm{~mm} \\
\text { Transparent: } 52 \mathrm{~mm}\end{array}$ \\
\hline Injection duration & $2 \mathrm{~ms}$ & Wall temperature & $423 \mathrm{~K}$ \\
\hline \multicolumn{2}{|c|}{ Fuel properties and conditions } & $8 \mathrm{ppm}$ \\
\hline Fuel & ULSD & Sulfur & 47.2 \\
\hline Density & $848 \mathrm{~kg} / \mathrm{m}^{3}$ & Cetane Index & $42.83 \mathrm{MJ} / \mathrm{kg}$ \\
\hline Viscosity & $2.6 \mathrm{cSt}$ & Temperature at nozzle & $363 \mathrm{~K}$ \\
\hline Carbon (wt \%) & 86.8 & Fuel injection pressure & $1200,1500,1800 \mathrm{bar}$ \\
\hline Hydrogen (wt \%) & 13.2 & \multicolumn{2}{|}{}
\end{tabular}

\section{Image processing}

Spray images for the front, side, and bottom views were processed with an in-house MATLAB code to obtain key spray properties such as spray tip penetration, impinged spray radii and height. First, the procedure starts with the background subtraction and images enhancement in order to achieve a better boundary detection of the spray. During the boundary detection, Otsu's threshold method [22], which provides a default threshold value, is used to convert the grayscale image into the binary image. A sensitivity analysis to the threshold has been performed in the previous study [20] to obtain the accurate spray boundary. Unnecessary shapes obtained in the binary image are filtered using morphological tools. Finally, the largest connected area obtained is considered for exact contouring of the spray boundary. After the boundary detection, the analytical parameters of the free and impinged spray properties are measured by extracting the extreme points of the binary Image. Figure 2 (top) shows the sample image processing for the front, side, and bottom views.

A schematic of spray boundaries along with nomenclatures is shown in Figure 2 (bottom). The free spray penetration $(Z)$ defines the extent of spray into the chamber before impinging on the wall. The spray angle $(\beta)$ is also measured based on the front view high-speed Mie-scattering images. The impinged spray characteristics include the impinged spray radius $(R)$ and impinged spray height $(H)$. For the front and side images, impinged spray radius is the maximum spread of the spray in the horizontal direction with respect to the impinging surface while impinged spray height is the maximum height formed after impingement with respect to the impinging surface.

The imaging analysis procedure from the bottom view image is quite different from the front and side impinging surface imaging analysis procedure. First, the precise location of the first impinging spray on the surface is identified as a reference origin to calculate the boundary of the wall-impinged expanding spray (WIES) front as shown in Figure 2 (bottom right). A 'centroid' method in the Matlab which is the mean position of all the points in the impinging 
spray was used to identify the first impinging origin. The boundary of the WIES front is traced by the same method used in the front and side view images. WIES radii in both the axial $\left(R_{S}\right)$ and radial $\left(R_{f}\right)$ directions are then defined as the distance between the origin and WIES front. In the WIES radius calculation for both the radial and axial directions, because the WIES front is highly wrinkled as it propagates on the surface of the wall, an additional procedure was taken for estimating the averaged radius over the arc sector. The final arc central angle is determined by varying the arc angle for the least sensitivity to the radius variation. It was found 30-degree for the least averaged radius variation over the entire impinging spray lifetime. In addition, the corrugation ratio can also be calculated by comparing the actual WIES front chord length over the corresponding smooth elliptic arc chord length, indicating the degree of the corrugated WIES front.
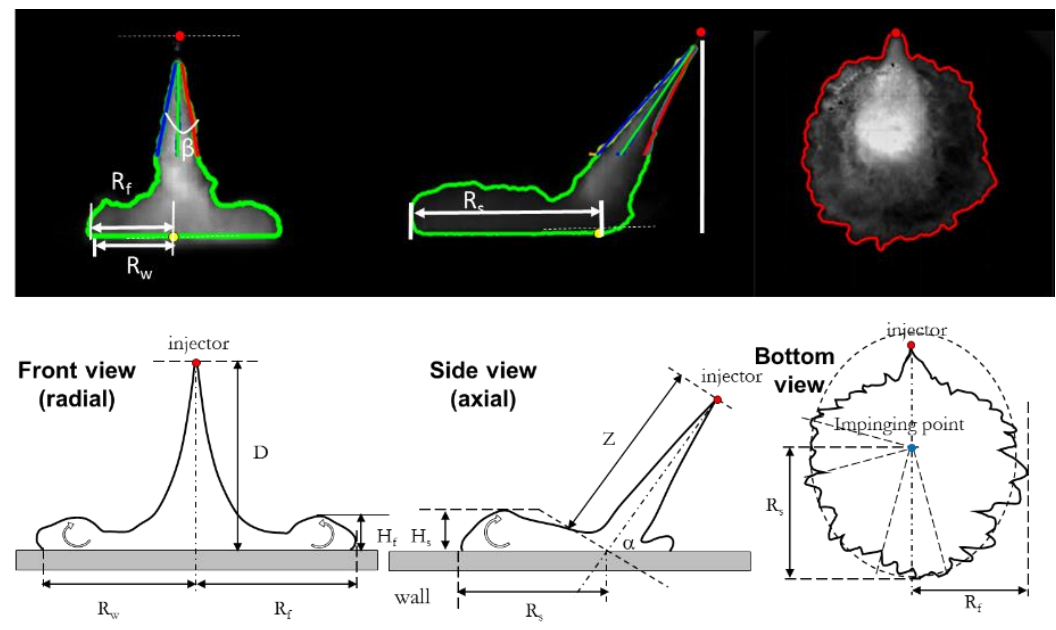

Figure 2. Images processing steps (top) and schematics of free and impinged spray (bottom). Nomenclature: $Z$ =free spray penetration; $R=$ =impinged spray radius; $H=$ =impinged spray height; $D=$ distance between injector and wall; $\beta=$ free spray dispersion angle; $\alpha=$ spray impacting angle. Subscript: $f=$ front; $s=s$ ide; $w=$ wall.

\section{Results and Discussion}

In general, fuel enters the chamber from the injector and spray experiences the normal free spray process before impinging on the wall. Liquid fuel disperses, breaks up, vaporizes, and mixes with air. The free spray contains two regions: main-jet region (particles with large velocities, momentum, and densities) and mixing flow region (air mixing expands the spray spatially). The main jet portion refers to the core region of the spray, and the mixing flow region stays outside the spray surrounding the main-jet region. The turbulence is generated because of air mixing, and particles in this region lose momentum in axial spray direction. Therefore, the core portion of the free spray has a higher velocity than the outer part. Then, all the droplets impinge on the wall with a certain angle (half of the included angle). Initially, the spray impinges on a dry wall, and the following interaction occurs between the spray and a wet wall. After impingement, the spray spreads on the plate around the impinging point and moves parallel to the plate. Droplets distributed near the plate show higher velocity and momentum than those farther from the plate due to the droplets near the plate come from the free spray core, which causes the velocity gradient and generates a vortex around the leading edge of spray. As a result, the rolling up motion enhances the air entrainment, lifts the lower momentum particles higher from the plate surface, and increases the height of impinged spray (see Figure 2 (bottom)). It is also found that the leading edge of the impinged spray is not along the wall but slightly higher away from the wall. The complicated turbulence environment and the distribution of droplets after impingement provide the possibility of collisions among droplets.

In this study, the injection rate was obtained by measuring the pressure wave generated when fuel is injected using Bosch rate of injection (ROI) meter [23]. ROI profile for energizing injection time of $2 \mathrm{~ms}$ at the injection pressure of 1500 bar is shown in Figure 3 (left), which was also selected as the experimental baseline condition. The corresponding injection duration is approximately $2.45 \mathrm{~ms}$. The total injected mass measured at ambient temperature is $28.39 \mathrm{mg}$ based on 3 repeats and the discharge coefficient is approximately 0.79 at the steady state. During spray-wall impingement, the velocity, momentum, and distribution of the spray before impingement are critical to the impinging behaviors. Injection pressure and ambient density influence the free spray penetration as well as the spray dispersion angle. The free penetration at an injection pressure of 1500 bar and different ambient densities are presented in Figure 3 (middle). The ambient density was varied from $14.8 \mathrm{~kg} / \mathrm{m}^{3}$ to $30 \mathrm{~kg} / \mathrm{m}^{3}$ and the experimental results are averaged from 5 runs. It can be observed that the penetration decreases 
as the ambient density increases at a given time. At the ambient density of $14.8 \mathrm{~kg} / \mathrm{m}^{3}$, spray impinges on the wall at the after the start of injection (ASOI) of $0.42 \mathrm{~ms}$, which is earlier than those at the higher ambient density. Figure 3 (right) provides the effect of injection pressure $\left(1200,1500\right.$, and $1800 \mathrm{bar}$ ) at the $22.8 \mathrm{~kg} / \mathrm{m}^{3}$ density. The penetration at the higher injection pressure shows the similar trend with the observation at the various densities at a fixed injection pressure, showing longer penetration than those at lower injection pressure. It is noted that the penetrations at the injection pressures of 1500 bar and 1800 bar show less difference than those at the injection pressures of 1200 bar and 1500 bar. At ASOI of $0.3 \mathrm{~ms}$, the free spray penetration at 1200 bar reaches $34 \mathrm{~mm}$, but the penetration at 1500 bar is around $37.5 \mathrm{~mm}$ which is close to the one at 1800 bar $(39 \mathrm{~mm})$. This would imply that the effect of injection pressure on the impinged spray becomes, to some extent, less as injection pressure increases. The penetration suggested by Naber et al. [24] is proportional to the $\left(P_{\mathrm{f}}-P_{\mathrm{a}}\right)^{1 / 4}$, where $P_{\mathrm{f}}$ is the injection pressure and $P_{\mathrm{a}}$ the ambient pressure. Assumed all the parameters remain constant, the only variable is $P_{\mathrm{f}}$ with three different cases: 1200 bar, 1500 bar, and 1800 bar. $P_{a}$ is 27.6 bar when the ambient density is $22.8 \mathrm{~kg} / \mathrm{m}^{3}$. $S_{1800 b a r}$ should be 1.04 times of $S_{1500 \mathrm{bar}}$ and $S_{1500 \mathrm{bar}}$ should be 1.06 times of $S_{1200 \mathrm{bar}}$, which confirms the experimental results.
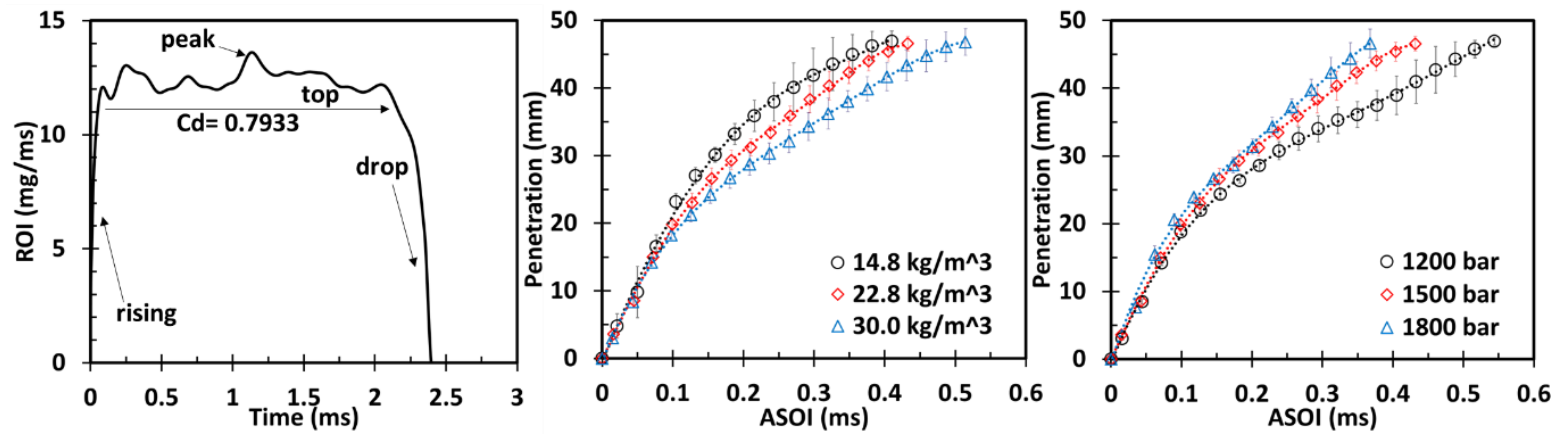

Figure 3. ROI profile at 1500 bar (left) and free spray penetrations at different ambient density with 1500 bar injection pressure (middle) and different injection pressure with $22.8 \mathrm{~kg} / \mathrm{m}^{3}$ density (right).

Figure 4 shows the effects of the ambient density (left) and injection pressure (right) on the spray dispersion angle. At the early stage of the injection, dispersion angle rises to a high value, and then a relative steady angle ( 23 degrees) establishes rapidly later. The large uncertainties underline the turbulent nature of the air entrainment process. From Figure 4 (left), the dispersion angle increases with the ambient density increase. In Figure 4 (right), however, it does not show a monotonic trend by the injection pressure. Before ASOI $1.3 \mathrm{~ms}$, dispersion angle at 1200 bar is the largest, next is the one at 1800 bar, and finally 1500 bar, implying no specific trend. After ASOI of $1.3 \mathrm{~ms}$, dispersion angles from all the conditions show the very small difference. Here, the larger dispersion angle indicates the higher level of air entrainment, since the entrainment is proportional to ambient air density, orifice diameter, fuel velocity, and spray dispersion angle [22]. Spray dispersion angle is a global parameter that describes the droplet distribution. Since in fact that the spray impingement obeys the stagnation flow model, the distribution of droplets before impacting affects their distribution after impingement.
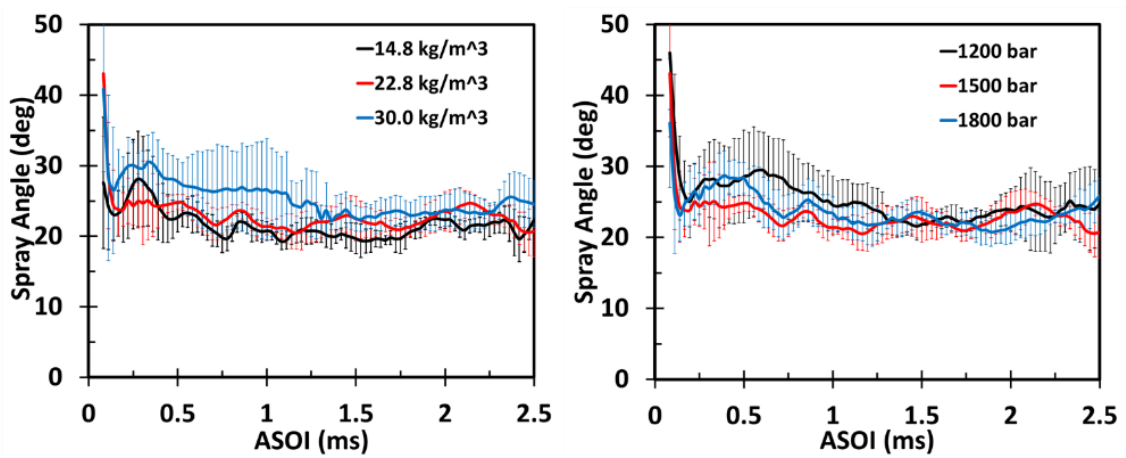

Figure 4. Spray dispersion angles at different ambient density with 1500 bar injection pressure (left) and different injection pressure with $22.8 \mathrm{~kg} / \mathrm{m}^{3}$ density (right).

Figure 5 (left) shows the effect of the ambient density on the WIES front radius for both axial and radial directions along with the time mark of the first impingement. The radius information was acquired from the bottom view image. Both directional radii start increasing after the first impingement, where the $14.8 \mathrm{~kg} / \mathrm{m}^{3}$ case impinges on the surface earlier than the other two ambient cases. Both radii increase until the end of injection where the actual rate of 
injection (ROI) ends at around ASOI $2.45 \mathrm{~ms}$, which is a similar observation of a stop of liquid film spread after the supply of the droplet to the film stopped [19]. The current test data did not catch this stop in radius changing due to the limitation of the chamber size. All the radii started with an initial value around $10 \mathrm{~mm}$ due to the overlap of impinged spray and free spray which causes the failure of the impinged radius calculation in earlier impinging time, the impinging time, however, is marked for different conditions in Figure 5.

Additionally, at the time of ASOI $2.5 \mathrm{~ms}$, axial radii reached $51.9 \mathrm{~mm}, 44.6 \mathrm{~mm}$, and $39.3 \mathrm{~mm}$ for ambient densities of $14.8,22.8$, and $30 \mathrm{~kg} / \mathrm{m}^{3}$, respectively. Both WIES radii tend to increase with the ambient density at the fixed time while the axial radius propagates faster than the radial radius regardless of the ambient density. The ratios of the axial and radial radii at the ASOI $2.5 \mathrm{~ms}$ are $1.5,1.44$ and 1.4 for the $14.8,22.8$, and $30 \mathrm{~kg} / \mathrm{m}^{3}$ cases, respectively, which results in oval shape impinged spray. This is partly attributed by higher axial velocity $(\sim 50 \%$ higher than the radial velocity) along the inclined plate (c.f. impact angle is 60-degree) when spray impinging, which elongates the axial impinged spray front than that in the radial direction. Figure 5 (right) reports the axial impinged height with various ambient densities. The height was measured by the side view schlieren images. Since the earlier impinged spray (i.e. around ASOI of $0.5 \mathrm{~ms}$ ) is highly complicated and mixed with the on-coming free spray, leading to a higher uncertainty. Initially, the impinged spray height increases fast, at the later time, the increasing rate slows down gradually and the impinged height reaches a maximum value. Similarly, the impinged height decreases as the ambient density raises.
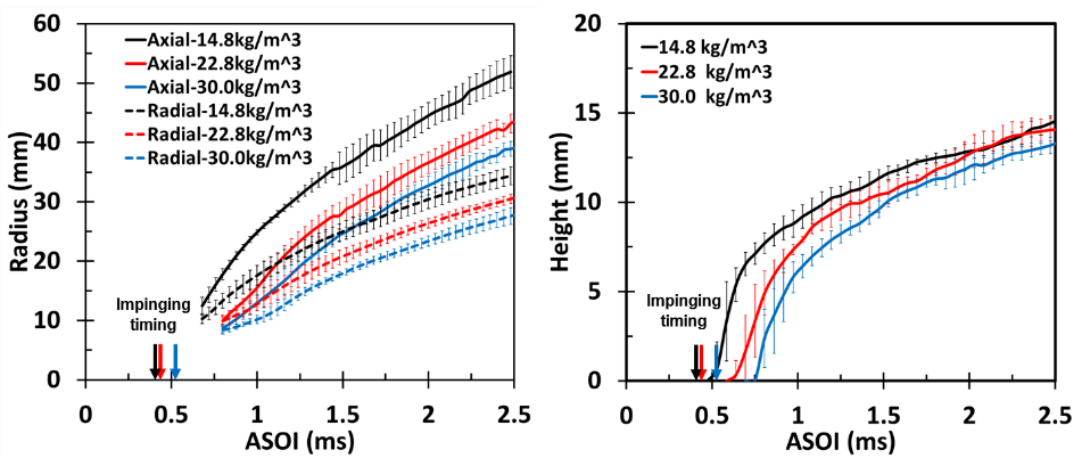

Figure 5. Impinged radii (left) and axial impinged heights (right) at different ambient density: $14.8,22.8$, and $30 \mathrm{~kg} / \mathrm{m}^{3}$.

Figure 6 provides the effect of injection pressure (1200, 1500, and 1800 bar) on WIES radius (left) and the WIES height (right) at the ambient density of $22.8 \mathrm{~kg} / \mathrm{m}^{3}$. Both axial and radial radii start increasing after the first impingement, where the 1800 bar case impinges on the surface earlier than the other two cases. The radii continue increasing up to the end of the injection around $2.45 \mathrm{~ms}$. Radial WIES radius at different injection pressures rises at a nearly same rate, but the axial radii increase with a steeper slope due to the higher velocity occurred in the axial direction as mentioned earlier. The ratios of the axial and radial radii at the ASOI $2.5 \mathrm{~ms}$ are $1.37,1.43$ and 1.41 for 1200, 1500, and 1800 bar cases, respectively, causing an oval shape of the impinged spray.

The directional radii and the WIES height tend to increase with the injection pressure at a fixed time. Because high injection pressure accelerates the free spray and thus causes the increase of impinged spray axial/radial expansion rates, and the WIES height. The proportionality between the impinged spray properties and the injection pressures are quite similar to the effect of ambient density but a sort of saturation appears at the 1800 bar in WIES height. This saturation behaves the same way as it is in the free spray penetration.
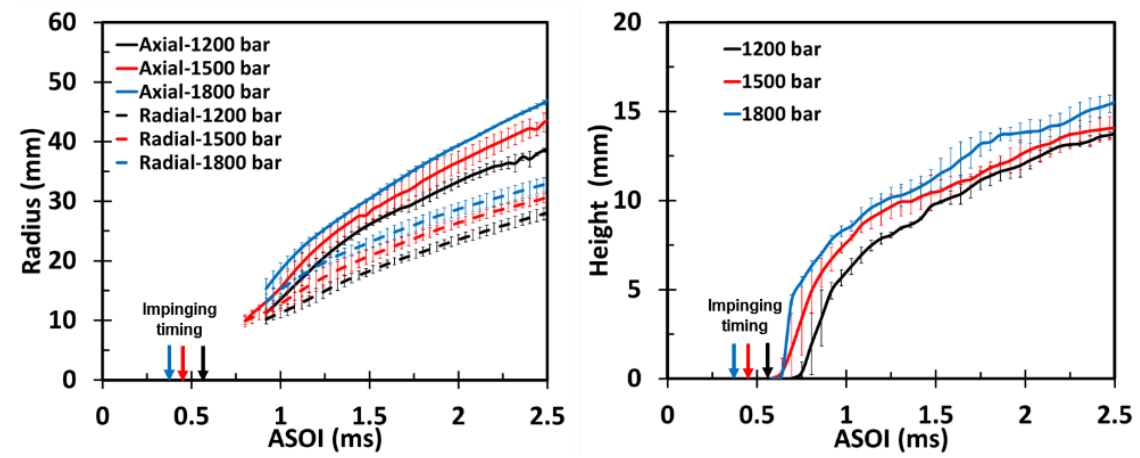

Figure 6. Impinged radii (left) and axial impinged heights (right) at different injection pressure: 1200, 1500, and 1800 bar. 
The temporal and spatial evolution of the WIES outer boundary and the corresponding axial WISE front speed profiles are shown in Figure 7. These boundaries were obtained from the bottom view imaging at a time interval of $40 \mu \mathrm{s}$ at the injection pressure of 1500 bar and $22.8 \mathrm{~kg} / \mathrm{m} 3$. The blank region in the center is the free spray projection on the plate, around which the actual boundaries of impinged spray are imposed. The origin is the impinging point. First, the WIES boundary displays a highly corrugated and complex front with the time increase, indicating the turbulent nature of the expanding spray interacted with the plate surface and surrounding ambient gas. The space between the two adjacent boundaries indicates the WIES expansion rate or speed that the larger the space the faster the spray expansion. The WIES expansion rate becomes smaller with time such that the boundaries away from the impinging point are much denser than those close to the impacting point. A substantial number of spikes (highly wrinkled boundaries) with time increase are randomly formed instead of staying at the same location, partly due to the injected flow rate fluctuation as seen in Figure 3 (left). There are spikes appeared after the first impingement, and then the subsequent spray, which generated more spikes at random locations, moved and merged with the previous spray continually. The interaction between the impinging sprays at the time shows a complicated WIES boundary development.

The axial expansion rates are also shown in Figure 7 after impingement. Since the impinging spray starts expanding parallel to the surface, the interaction between the impinging spray and wall/air retard the horizontal propagation across the surface. Expansion rate decreases from $40 \mathrm{~m} / \mathrm{s}$ to $10 \mathrm{~m} / \mathrm{s}$ within $2.5 \mathrm{~ms}$ and the similar spray-leading rate is shown regardless of ambient density (middle) and injection pressure (right). The power-law curve-fit equations show the similar amplitude and power for both injection pressure and density cases. Based on these equations, the WIES expansion process is divided into four stages: rapidly decelerated stage (before ASOI $1.2 \mathrm{~ms}$ ), slowly decreasing stage (ASOI 1.2 to $2 \mathrm{~ms}$ ), relatively constant stage (after ASOI $2 \mathrm{~ms}$ ), and expanding termination stage (not shown in Figure 7).
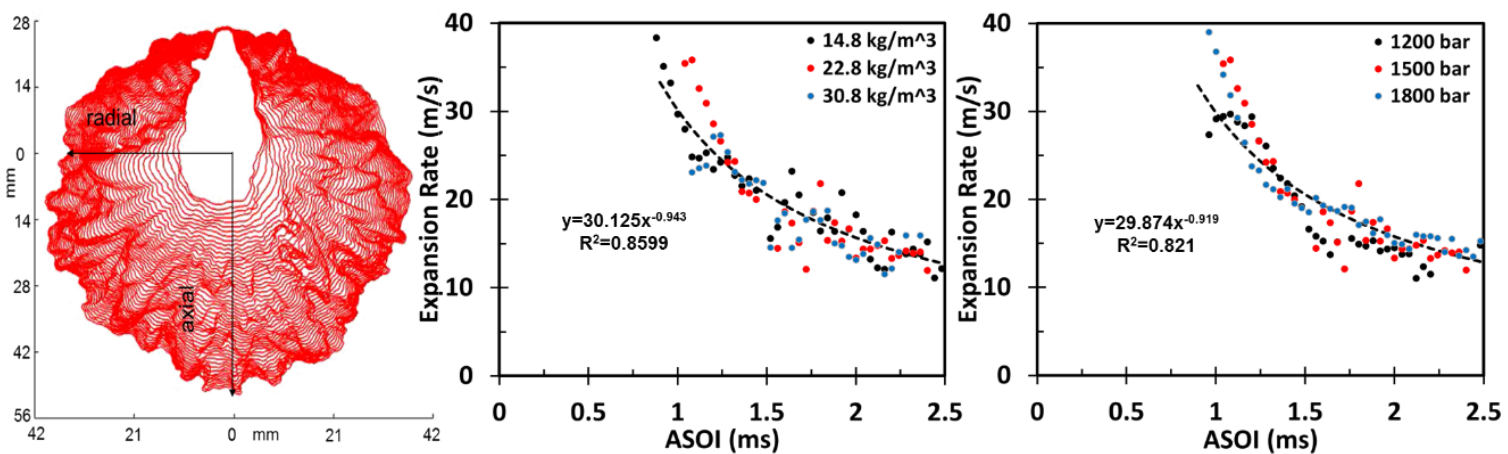

Figure 7. Evolution of the WIES outer boundary (left) and the expansion rate of WIES after impingement at different ambient densities (middle); at different injection pressures (right).

\section{Summary}

The spray impingement test was performed in a well-controlled vessel using a single-hole injector (60-degree impact angle) to characterize the impinged spray on a flat plate with the combined condition of injection pressures $(1200 / 1500 / 1800 \mathrm{bar})$ and ambient densities $\left(14.8 / 22.8 / 30 \mathrm{~kg} / \mathrm{m}^{3}\right)$ at isothermal conditions. The simultaneous Mie scattering and schlieren images were acquired for the liquid spray development and spray-wall interaction. An inhouse Matlab code for image processing was developed to extract the free and impinged spray properties.

Several observations can be made from the experiment. (1) The WIES expansion process is divided into four stages: rapidly decelerated stage, slowly decreasing rate stage, relatively constant rate stage, and expanding termination stage. (2) The WIES front has complicated, highly wrinkled structures as it propagates on the plate surface. The evolution of the WIES showed the boundary spikes which are formed at random locations. (3) The averaged radius of WIES was calculated over a 30-degree angle arc which was found having the least averaged radius variation. This arc-angle based radius method compensates for the wrinkled effect of the WIES front. (4) The effect of ambient density and injection pressure on the free and impinged spray were explored. Both lower ambient density and higher injection pressure intensify the free spray dispersion, impinged spray expansion, and lead to higher impinged spray height. Free spray angle increases with ambient density but is not significantly affected by injection pressure. Similarly, the WIES expansion rates on the wall showed no obvious dependence of the ambient density and the injection pressure. (5) The magnitude of the temporal axial radius is larger than that of the radial radius because of the higher momentum in the axial direction when spray impinges on the wall. The relative ratios of the axial radius to the radial radius are around 1.4 , resulting in the oval impinged spray. 


\section{Acknowledgements}

This material is based upon work supported by the Department of Energy, Office of Energy Efficiency and Renewable Energy (EERE) and the Department of Defense, Tank and Automotive Research, Development, and Engineering Center (TARDEC), under Award Number DE-EE0007292.

\section{References}

[1] Nauwerck, A., Pfeil, J., Velji, A., Spicher, U., and Richter, B., 2005, "A basic experimental study of gasoline direct injection at significantly high injection pressures," No. 0148-7191, SAE Technical Paper.

[2] Abart, M., Schmidt, S., Schoegl, O., Trattner, A., Kirchberger, R., Eichlseder, H., and Jajcevic, D., 2010, "Basic Investigations on the Prediction of Spray-Wall and Spray-Fluid Interaction for a GDI Combustion Process," No. 0148-7191, SAE Technical Paper.

[3] Alfuso, S., Allocca, L., Greco, M., Montanaro, A., and Valentino, G., 2008, "Time-and Space Characterization of Multi-hole GDI Sprays for IC Engines by Images Processing and PDA Techniques," Jets, 20, p. 21.

[4] Stanton, D. W., and Rutland, C. J., 1996, "Modeling fuel film formation and wall interaction in diesel engines," No. 0148-7191, SAE Technical Paper.

[5] Stanglmaier, R. H., Li, J., and Matthews, R. D., 1999, "The effect of in-cylinder wall wetting location on the HC emissions from SI engines," No. 0148-7191, SAE Technical Paper.

[6] Drake, M. C., Fansler, T. D., Solomon, A. S., and Szekely, G., 2003, "Piston fuel films as a source of smoke and hydrocarbon emissions from a wall-controlled spark-ignited direct-injection engine," No. 0148-7191, SAE Technical Paper.

[7] Stevens, E., and Steeper, R., 2001, "Piston wetting in an optical DISI engine: fuel films, pool fires, and soot generation," No. 0148-7191, SAE Technical Paper.

[8] Sandquist, H., Lindgren, R., and Denbratt, I., 2000, "Sources of hydrocarbon emissions from a direct injection stratified charge spark ignition engine," No. 0148-7191, SAE Technical Paper.

[9] Cheng, W. K., Hamrin, D., Heywood, J. B., Hochgreb, S., Min, K., and Norris, M., 1993, "An overview of hydrocarbon emissions mechanisms in spark-ignition engines," No. 0148-7191, SAE Technical Paper.

[10] Alkidas, A. C., 1994, "The effects of fuel preparation on hydrocarbon emissions of a SI engine operating under steady-state conditions," No. 0148-7191, SAE Technical Paper.

[11] Alkidas, A., and Drews, R., 1996, "Effects of mixture preparation on HC emissions of a si engine operating under steady-state cold conditions," No. 0148-7191, SAE Technical Paper.

[12] Fox, J., Min, K. D., Cheng, W., and Heywood, J. B., 1992, "Mixture preparation in a SI engine with port fuel injection during starting and warm-up," No. 0148-7191, SAE Technical Paper.

[13] Fulcher, S. K., Gajdeczko, B., Felton, P., and Bracco, F., 1995, "The effects of fuel atomization, vaporization, and mixing on the cold-start UHC emissions of a contemporary SI engine with intake-manifold injection," No. 01487191, SAE Technical Paper.

[14] Zhao, L., Torelli, R., Zhu, X., Scarcelli, R., Som, S., Schmidt, H., Naber, J., and Lee, S.-Y., 2017, "An experimental and numerical study of diesel spray impingement on a flat plate," SAE International Journal of Fuels and Lubricants, 10(2017-01-0854).

[15] Zhang, Y., Jia, M., Liu, H., Xie, M., Wang, T., and Zhou, L., 2014, "Development of a new spray/wall interaction model for diesel spray under PCCl-engine relevant conditions," Atomization and Sprays, 24(1).

[16] Siewert, R. M., 2007, "Spray angle and rail pressure study for low NOx diesel combustion," No. 0148-7191, SAE Technical Paper.

[17] Akop, M. Z., Zama, Y., Furuhata, T., and Arai, M., 2013, "Characteristics of adhesion of diesel fuel on impingement disk wall. Part 1: effect of impingement area and inclination angle of disk," Atomization and Sprays, 23(8).

[18] Lindagren, R., and Denbratt, I., 2004, "Influence of wall properties on the characteristics of a gasoline spray after wall impingement," No. 0148-7191, SAE Technical Paper.

[19] Montorsi, L., Magnusson, A., and Andersson, S., 2006, "A numerical and experimental study of diesel fuel sprays impinging on a temperature controlled wall," No. 0148-7191, SAE Technical Paper.

[20] Senda, J., Ohnishi, M., Takahashi, T., Fujimoto, H., Utsunomiya, A., and Wakatabe, M., 1999, "Measurement and modeling on wall wetted fuel film profile and mixture preparation in intake port of SI engine," No. 0148-7191, SAE Technical Paper.

[21] Montanaro, A., Allocca, L., Meccariello, G., and Lazzaro, M., 2015, "Schlieren and Mie Scattering Imaging System to Evaluate Liquid and Vapor Contours of a Gasoline Spray Impacting on a Heated Wall," No. 0148-7191, SAE Technical Paper.

[22] Otsu, N., 1975, "A threshold selection method from gray-level histograms," Automatica, 11(285-296), pp. 2327.

[23] Bower, G. R., and Foster, D. E., 1991, "A comparison of the Bosch and Zuech rate of injection meters," No. 0148-7191, SAE Technical Paper.

[24] Naber, J. D., and Siebers, D. L., 1996, "Effects of gas density and vaporization on penetration and dispersion of diesel sprays," No. 0148-7191, SAE technical paper. 